\title{
ADSORÇÃO DO CORANTE EOSINA A PARTIR DE SOLUÇÃO AQUOSA UTILIZANDO CASCAS DE MARISCO ANOMALOCARDIA BRASILIANA
}

\author{
S. ANTERINO ${ }^{1}$, T. M. N. PAIVA ${ }^{1}$, P. SILVA ${ }^{1}$, L. C. ZOBY ${ }^{1}$, J. M. FERREIRA ${ }^{1}$, M. A. MOTTA \\ SOBRINHO $^{1}$ \\ ${ }^{1}$ Universidade Federal de Pernambuco, Departamento de Engenharia Química \\ E-mail para contato: tarsilamaira@hotmail.com
}

RESUMO - Remoção de cor de efluentes industriais é uma das necessidades mais difíceis enfrentadas pelo setor têxtil, fabricação de corantes, indústrias de papel e celulose, fármacos entre outras. Sendo assim, foi considerado desenvolver um método econômico e rápido para remoção de corantes de águas residuais. O desempenho de resíduos da maricultura, conchas de marisco anomalocardia brasiliana, foi investigado para a adsorção do corante Eosina amarela em solução aquosa. Este corante é de natureza aniônica e é altamente tóxico. Os efeitos que a agitação, granulometria e quantidade de massa do adsorvente exercem sobre o processo adsortivo foram avaliados através da técnica de planejamento fatorial. Foram preparadas em Erlenmeyers de 50 $\mathrm{mL}, 25 \mathrm{~mL}$ de soluções a $15 \mathrm{ppm}$ do corante Eosina, as quais foram mantidas sob agitação constante durante 30 minutos. As melhores condições para capacidade de adsorção foram com 0,5 g de adsorvente a 100 mesh tratado termicamente a $1000{ }^{\circ} \mathrm{C}$ e $150 \mathrm{rpm}$. Sob as condições de estudo, a remoção do corante Eosina amarela por conchas de marisco apresentou bons resultados, cerca de $86 \%$ de eficiência, podendo este adsorvente ser empregado como alternativa para a remoção de corantes em efluentes têxteis.

\section{INTRODUÇÃO}

Eosina Amarela é um corante aniônico altamente solúvel em água e pertence à classe de corantes fluoresceína. Devido à sua capacidade de absorção forte por células vermelhas do sangue, este corante é amplamente utilizado na coloração de Gram para diferenciação de espécies bacterianas. A informação toxicológica de Eosina amarela revela que pode causar grave irritação na pele e nos olhos. Após ingestão, pode provocar vários efeitos adversos sobre órgãos vitais como o fígado e rim. Ele também causa danos ao DNA de órgãos gastrointestinais trazendo risco de várias doenças. Inalação do corante reduz a capacidade de troca gasosa dos pulmões. Seus metabólitos também são altamente tóxicos e cancerígenos na natureza (Mittal et al., 2013). Este corante também é utilizado para dar coloração avermelhada com fluorescência em tecidos de lã (Purkaitet al., 2005).

A descarga de corantes para o fluxo de águas sem tratamento adequado causa danos irreparáveis ao meio ambiente e os seres vivos, tanto aquáticos como terrestres (Purkait et al., 2005).

A remoção da Eosina foi estudada por Chatterjee et al., (2001), utilizando a combinação de 


\section{9 a 22 de outubro de 2014 \\ Florianópolis/SC}

processos fotocatalíticos e adsortivos, obtendo remoções de $83,2 \%$ com $6 \mathrm{~g}$ de cinzas volantes. Já Pereira et al., (2013) avaliaram a sua degradação utilizando um reator fotocatalítico plano com degradação de $73 \%$ da oesina em $\mathrm{pH}$ 7,0 com uma concentração inicial de $0,3 \mathrm{mM} \cdot \mathrm{L}^{-1}$.

Zhang et al. (2013) estudaram a adsorção de Eosina em filmes nanocristalino de $\mathrm{TiO}_{2}$ para aumentar a eficiência de fotocélulas, a qual foi obtida com a manipulação da configuração de adsorção. Chatterjee et al. (2005) avaliaram a adsorção da Eosina utilizando um leito condicionado de quitosana, obtendo uma capacidade de remoção de $76 \mathrm{mg} \cdot \mathrm{g}^{-1}$.

No princípio a maricultura foi vista como uma alternativa de complementação de renda para os pescadores artesanais, mas, com o decorrer dos anos, passou a ser fonte de renda principal e também um forte passivo ambiental próximo às áreas dessa prática (Icepa, 2004).

Em Pernambuco, em áreas costeiras, os manguezais sofrem com a poluição ambiental em vários pontos são encontradas grandes quantidades de resíduo da maricultura, que, por ser um resíduo natural pode não parecer uma fonte poluição, mas esse tipo de lixo vem causando prejuízo aos manguezais e aos rios destas regiões (Bochese et al., 2008). Em locais onde existe depósito desses resíduos, as margens dos rios ficam aterradas, interferindo em toda a dinâmica do manguezal (Borges, 2010). De acordo com a CPRH, não há nenhum projeto de beneficiamento desses resíduos naturais.

Conceitualmente, afirmam Chatterjee et al. (2001), a combinação de mais de um processo, como a adsorção e a degradação oxidativa, podem promover uma remoção da cor de forma viável, técnica e economicamente. Devido às implicações ambientais citadas, tecnologias têm sido estudadas para a degradação ou imobilização desses compostos em efluentes (Rutz et al., 2008).

\section{MATERIAIS E MÉTODOS}

\subsection{Materiais}

Foi utilizado o corante aniônico Eosina amarela (C.I. 45380), cuja estrutura está representada na Figura 1, é um xanteno, com comprimento de onda máximo de $515 \mathrm{~nm}$, obtida pela medição da absorbância em um espectrofotômetro (UV-visível ThermoGenesys 10).

Os adsorventes utilizados nesse estudo foram conchas de marisco da espécie Anomalocardia brasiliana (Figura 2), coletadas no litoral norte de Pernambuco. As conchas foram lavadas em água corrente para retirar o excesso de sal e resíduos orgânicos. Posteriormente foram secas em estufa por 3 horas a $60^{\circ} \mathrm{C}$ com o intuito de reduzir sua umidade, para dar prosseguimento ao processo de moagem.

$\mathrm{O}$ adsorvente foi triturado em moinho de rolos e classificado em peneiras da série de Tyler 20,60 e 100 mesh. Foi realizado tratamento térmico em mufla à temperatura de $1000^{\circ} \mathrm{C}$ por 3 horas (PAIVA, 2011). 
<smiles>NC(=O)c1ccccc1-c1c2cc(Br)c(=O)c(Br)c-2oc2c(Br)c([O-])c(Br)cc12</smiles>

Figura 1 - Estrtura da Eosina (Chatterjee et al.,2001) Figura 2 - Foto das conchas utilizadas

\subsection{Métodos}

\section{$\underline{\text { Planejamento Fatorial dos Experimentos }}$}

A capacidade adsortiva das conchas de marisco foi avaliada pela técnica de planejamento experimental, em que foram investigados alguns dos principais fatores que mais influenciam no processo adsortivo: a quantidade do adsorvente (M), a velocidade de agitação (A) e a granulometria do adsorvente $(\mathrm{G})$.

Para a variável tempo de contato, foram realizados os testes preliminares, os quais revelaram que a adsorção do corante sobre o adsorvente é rápida. Nesse estudo foram escolhidos os níveis para cada variável, conforme os critérios encontrados na literatura (PAIVA et al., 2011).

Dessa forma foi realizado um planejamento fatorial $2^{3}$ completo, acrescido de um ponto central em triplicata, totalizando, assim, 11 experimentos. Os níveis das variáveis estudadas encontram-se na Tabela 1.

Tabela 1 -Variáveis e níveis estudados no planejamento fatorial $2^{3}$

\begin{tabular}{|c|c|c|c|}
\hline \multirow{2}{*}{ Variáveis } & \multicolumn{3}{|c|}{ Níveis } \\
\cline { 2 - 4 } & -1 & 0 & +1 \\
\hline Massa (g) & 0,5 & 1,25 & 2,0 \\
\hline Granulometria (mesh) & 100 & 60 & 20 \\
\hline Agitação (rpm) & 150 & 300 & 450 \\
\hline
\end{tabular}

Os experimentos foram realizados em duplicata e em ordem aleatória e a resposta estudada foi a capacidade adsortiva, ou seja, quantidade de corante adsorvida por unidade de massa do adsorvente $(Q)$. A capacidade adsortiva é calculada pela Equação 1. 


$$
Q=\frac{\left(C_{A 0}-C_{A}\right)}{M} x V
$$

na qual $C_{A 0}$ é a concentração inicial de adsorvato $\left(\mathrm{mg} \cdot \mathrm{L}^{-1}\right), C_{A}$ é a concentração final de adsorvato (mg. $\left.\mathrm{L}^{-1}\right), V$ é o volume da solução de corante (L) e $M$ é a massa de adsorvente (g).

\section{Eficiência de Adsorção}

A eficiência de adsorção foi determinada a partir da concentração final do corante alcançada após o intervalo de tempo de reação na melhor condição do planejamento fatorial. Para verificar a eficiência na remoção do corante, após o processo de adsorção, utilizou-se a Equação 2.

$$
e=\frac{\left(C_{A 0}-C_{A}\right)}{C_{A 0}} x 100
$$

na qual e é a eficiência do processo, $C_{\mathrm{A} 0}$ é concentração inicial de adsorvato (mg. $\mathrm{L}^{-1}$ ) e $\mathrm{C}_{\mathrm{A}}$ é concentração final de adsorvato $\left(\mathrm{mg} . \mathrm{L}^{-1}\right)$.

\section{RESULTADOS E DISCUSSÃO}

\section{Planejamento Fatorial}

A Tabela 2 apresenta a matriz de planejamento com a média dos resultados obtidos da variável resposta $(Q)$ em cada combinação de níveis para as variáveis de entrada, referente aos ensaios, utilizando as conchas de marisco termicamente tratadas como adsorvente na remoção do corante Eosina. Pode-se verificar que as maiores capacidades, foram obtidas para as menores massas, indicando que para o nível superior deste parâmetro não houve saturação do adsorvente. Pode-se ainda inferir que a granulometria de 20 mesh apresentou uma capacidade ligeiramente superior às demais e que a agitação maior favoreceu a adsorção.

Tabela 2 - Matriz de planejamento para um fatorial $2^{3}$

\begin{tabular}{|c|c|c|c|c|}
\hline Ensaios & Agitação $(\mathrm{g})$ & Granulometria (mesh) & Massa (rpm) & $Q\left(\mathrm{mg}^{-1} \mathrm{~g}^{-1}\right.$ \\
\hline 1 & + & + & + & 0,184 \\
\hline 2 & + & + & - & 0,687 \\
\hline 3 & + & - & + & 0,184 \\
\hline 4 & + & - & - & 0,655 \\
\hline 5 & - & + & + & 0,183 \\
\hline 6 & - & + & - & 0,671 \\
\hline 7 & - & - & + & 0,184 \\
\hline 8 & - & - & - & 0,638 \\
\hline 9 & 0 & 0 & 0 & 0,296 \\
\hline 10 & 0 & 0 & 0 & 0,296 \\
\hline
\end{tabular}


0

0,297

+) 2,0 g, 20 mesh, $450 \mathrm{rpm}$; -) 0,5 g, 100 mesh, $150 \mathrm{rpm}$;) 1,25 g, 60 mesh, $300 \mathrm{rpm}$

Pelos valores observados na Tabela 3 verificou-se que, o sistema em estudo apresentou um elevado valor de \% de variância explicável, ou seja, uma menor quantidade de resíduos, mostrando assim, um bom ajuste ao modelo matemático aplicado (Barros Neto et al., 2007).

A Tabela 3 mostra a avaliação do modelo pela metodologia da análise de variância (ANOVA), considerando as repetições dos experimentos, a qual indica que o modelo é estatisticamente significativo, pois ao serem comparados os valores dos testes $\mathrm{F}$ calculado e o tabelado obtém-se uma razão de 11,51 para a regressão, e segundo Barros Neto et al. (2007) quando essa razão é maior que 1 o modelo é estatisticamente significativo e maior de 5 é preditivo. O coeficiente de correlação múltipla $\left(R^{2}\right)$ foi igual a $0,97 \%$.

Tabela 3 - Avaliação Estatística do Planejamento Experimental

\begin{tabular}{|c|c|c|c|}
\hline Fonte de Variação & $\begin{array}{c}\text { Soma } \\
\text { Quadrática }\end{array}$ & $\begin{array}{c}\text { Números de Graus } \\
\text { de Liberdade }\end{array}$ & $\begin{array}{c}\text { Média } \\
\text { Quadrática }\end{array}$ \\
\hline Regressão & 0,982858421 & 6 & 0,1638 \\
\hline Resíduos & 0,038014181 & 9 & 0,0042 \\
\hline Falta de Ajuste & 0,037994 & 2 & 0,0190 \\
\hline Erro Puro & 0,000020 & 9 & 0,0000 \\
\hline Total & 1,020873 & 17 & \\
\hline $\mathrm{F}_{\text {calc }}$ & 38,78 & & \\
\hline $\mathrm{F}_{\text {tabelado }}$ REG & 3,37 & & \\
\hline$\% \mathrm{Mx}$. Explicada & 96,28 & & \\
\hline$\% \mathrm{Mx}$. Explicável & 100,00 & & \\
\hline $\mathrm{R}^{2}$ & 0,97 & & \\
\hline $\mathrm{F}_{\text {calculado }} \cdot \mathrm{F}_{\text {tabelado }}{ }^{-1}$ & 11,51 & & \\
\hline & & & \\
\hline
\end{tabular}

Através da regressão dos dados experimentais, foi possível obter um modelo matemático linear codificado para o sistema experimental analisado. Este modelo pode ser representado por uma equação empírica como a ilustrada na Equação 2.

$Q=0,397813-0,004477$ A $-0,012239$ G $-0,247351 \mathrm{M}+0,001453$ A G + 0,005922 A M + 0,006270 GM

Observa-se pela Equação 2 que o quarto termo representou uma influência negativa da quantidade de massa do adsorvente sobre a quantidade adsorvida, ou seja, à medida que se diminui a quantidade de massa obtém-se um elevado valor de Q. Este fato pode ser observado por se trabalhar dentro da faixa de condições ótimas. O segundo e terceiro termos, agitação e granulometria também exerceram efeito negativo na quantidade adsorvida $(\mathrm{Q})$, porém em menor escala, ou seja, quanto maior o mesh (menor granulometria) e menor agitação, maior será Q. 
A influência dos efeitos significativos no modelo foi representada graficamente pelo gráfico de Pareto exposto na Figura 3, o qual comprova que a variável de maior influência nesse processo adsortivo foi a quantidade de adsorvente $(\mathrm{M})$, seguida da granulometria $(\mathrm{G})$ e agitação (A).

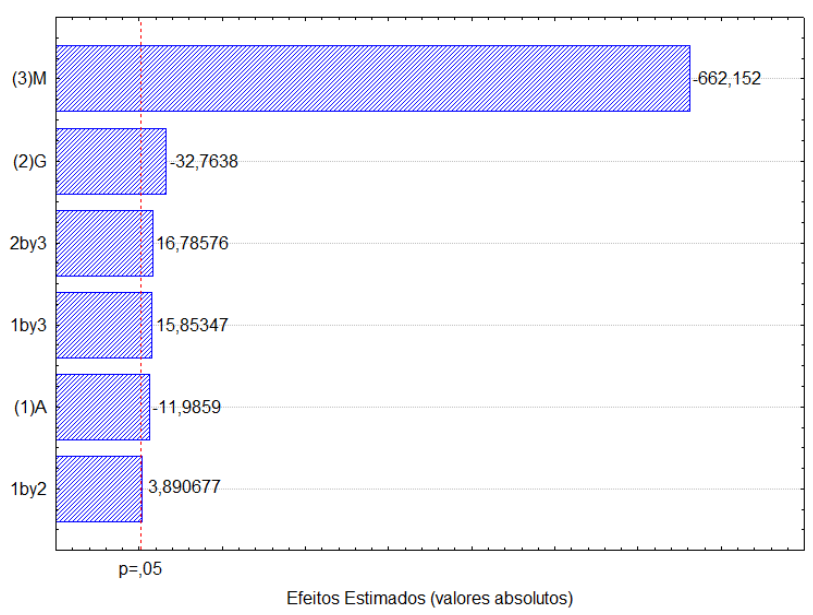

Figura 3 - Gráfico de Pareto referente ao Planejamento

A Figura 4 mostra a superfície de resposta e a curvas de níveis geradas com auxílio o programa Statistica for Windows 5.0, com o uso dos dados obtidos experimentalmente, após uma otimização por planejamento experimental $2^{3}$. Pode-se confirmar a influência significativa da quantidade de adsorvente $(\mathrm{M})$, e, com menor influência, da granulometria $(\mathrm{G})$, observados no gráfico de Pareto (Figura 3). Constata-se ainda que com o aumento da quantidade de adsorvente e da granulometria em mesh obteve-se o valor máximo da quantidade adsorvida $(Q)$. 


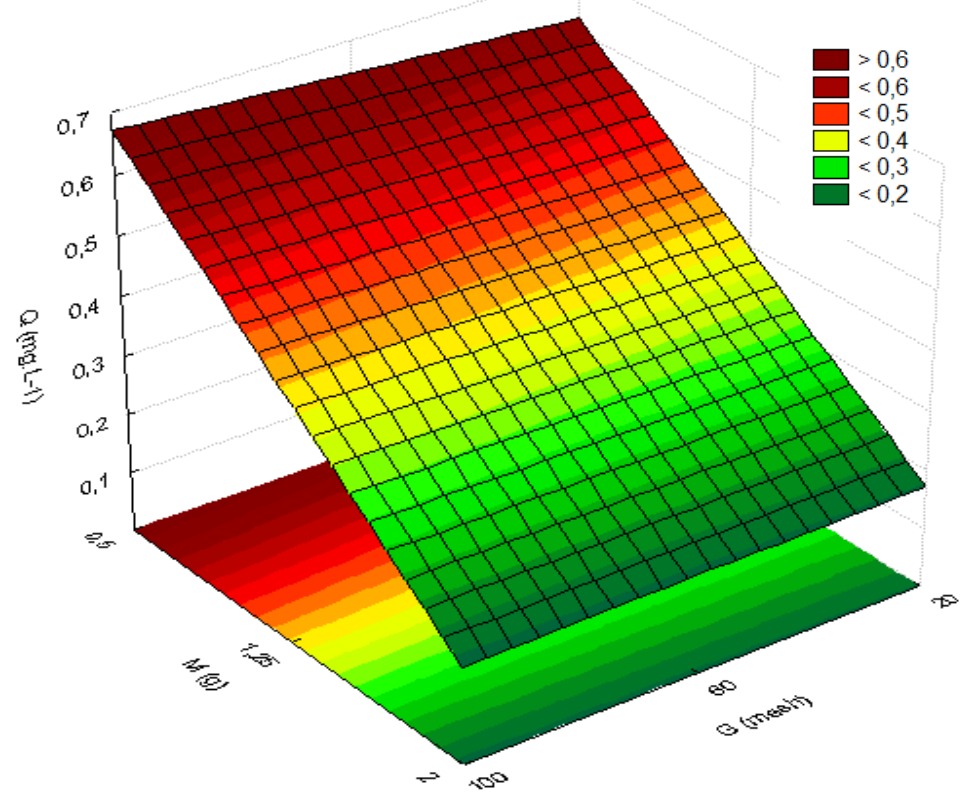

Figura 4 - Efeito da quantidade de adsorvente (M) e granulometria (G) sobre a quantidade adsorvida do Eosina por unidade de massa do adsorvente conchas de marisco

O valor máximo da quantidade de corante adsorvida $(Q)$ foi de aproximadamente 0,638 $\mathrm{mg} . \mathrm{g}^{-1}$ nas seguintes condições: quantidade de adsorvente (M) 0,5 g, granulometria (G) 100 mesh e velocidade de agitação (A) $150 \mathrm{rpm}$.

\section{Eficiência de adsorção}

A eficiência de remoção do corante Eosina do meio aquoso pelas conchas de marisco foi de $85 \%$.

\section{CONCLUSÃO}

Para as condições experimentais aplicadas neste trabalho constatou-se que as conchas do marisco Anomalocardia brasilianapode pode ser uma atrativa opção para remoção de corantes em efluentes de indústria têxtil, uma vez que se destaca pelo seu poder de aquisição relativamente baixo quando comparado com outros tipos de adsorventes. A eficiência do processo foi de $85 \%$.

Pelo método de planejamento experimental conclui-se que a variável que mais influenciou no processo de adsorção foi a quantidade do adsorvente (M). As melhores relações entre a remoção do corante e capacidade de adsorção do adsorvente são obtidas com a concha ativada a $1000{ }^{\circ} \mathrm{C}$ calcinadas a 3horas, quantidade de adsorvente (M) de $0,5 \mathrm{~g}$, granulomertia (G) de 100 
mesh e velocidade de agitação (A) de $150 \mathrm{rpm}$. O valor máximo da quantidade adsorvida nas condições estudadas foi de $0,638 \mathrm{mg} \cdot \mathrm{g}^{-1}$.

\section{REFERENCIAS}

BARROS NETO, B.; SCARMINIO, I. S.; BRUNS, R. E. Como fazer experimentos: pesquisa e desenvolvimento na ciência e na indústria. v.1, 4.ed. Coleção Livros-Textos, Campinas: UNICAMP, 2007. 480 p.

BOCCHESE, D. F.; ARAÚJO, E. M.; SANT'ANNA, F. S. P. Projeto valorização dos resíduos da maricultura: eliminação de matéria orgânica de conchas de ostras por processo biológico.Universidade Federal de Santa Catarina, Florianópolis-SC, 2008.

BORGES, S. Latão em Igarassu: Rio São Domingos tem até sofá. Recife, nov. 2010. Disponível em: <http://migre.me/3MpFu>. Acessoem: 02/12/2010.

CHATTERJEE, D., RUJ, B., MAHATA, A., Adsorption ond photocatalysis of color removal from wastewater using flyash and sunlight. Catalysis Communications. v. 2, p.113-117, 2001.

CHATterJeE, S., CHATTERJEE, S., CHATTERJEE, B.P., DAS, A.R., GUHA, A.K. Adsorption of a model anionic dye, eosin Y, from aqueous solution by chitosan hydrobeads. J Colloid Interface Sci., v. 288, n.1, p.30-35, 2005.

ICEPA - Comissão Estadual de Planejamento Agrícola-SC. Síntese Anual da Agricultura Catarinense. Florianópolis-SC, 321 p., 2004.

MITTAL, A.; JHARE, D.; MITTAL, J. Adsorption of hazardous dye Eosin Yellow from aqueous solution onto waste material De-oiled Soya: Isotherm, kinetics and bulk removal. Journal of Molecular Liquids. v. 179, p. 133-144.

PEREIRA, L., PEREIRA, R., OLIVEIRA, C.S., APOSTOL, L., GAVRILESCU, M., PONS, M.N, ZAHRAA, O., ALVES, M.M. UV/TiO 2 Photocatalytic Degradation of Xanthene Dyes. Photochemistry and Photobiology, v. 89, p.33-39, 2013.

PURKAIT, M. K.; DASGUPTA; DE, S. Adsorption of eosin dye on activated carbon and its surfactant based desorption. Journal of Environmental Management. v. 76, p. 135-142.

RUTZ, E. G.; CARVALHO, C. F.; PIRES, C. S.; CURIEL, G.L. Adsorção do corante têxtil Amarelo remazol usando um dos rejeitos da fabricação da alumina como adsorvente. Revista Escola de Minas.v. 61. n. 4, p. 443-448, 2008.

ZHANG, F., SHI, F., MA, W., GAO, F., JIAO, Y., LI H., WANG, J., SHAN, X., LU, X., MENG, S. Controlling Adsorption Structure of Eosin Y Dye on Nanocrystalline $\mathrm{TiO}_{2}$ Films for Improved Photovoltaic Performances. J. Phys. Chem. C, v. 117, n. 28, p. 14659-14666, 2013. 